\title{
Transatlantica
}

Revue d'études américaines. American Studies Journal

\section{Helen Levitt, photographe américaine, 1913-2009}

Jean Kempf

\section{(2) OpenEdition}

\section{Journals}

Édition électronique

URL : https://journals.openedition.org/transatlantica/4305

DOI : $10.4000 /$ transatlantica.4305

ISSN : 1765-2766

Éditeur

Association française d'Etudes Américaines (AFEA)

Référence électronique

Jean Kempf, « Helen Levitt, photographe américaine, 1913-2009», Transatlantica [En ligne], 1 | 2009, mis en ligne le 19 juillet 2009, consulté le 15 septembre 2021. URL : http://journals.openedition.org/ transatlantica/4305; DOI : https://doi.org/10.4000/transatlantica.4305

Ce document a été généré automatiquement le 15 septembre 2021.

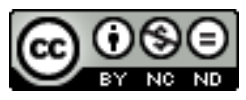

Transatlantica - Revue d'études américaines est mise à disposition selon les termes de la licence Creative Commons Attribution - Pas d'Utilisation Commerciale - Pas de Modification 4.0 International. 


\title{
Helen Levitt, photographe américaine, 1913-2009
}

\author{
Jean Kempf
}

1 Helen Levitt, qui vient de disparaitre à 95 ans, était une figure discrète mais importante de la photographie américaine de l'après-guerre. Ni passionaria du documentaire comme avait pu l'être Dorothea Lange, ni militante d'un art photographique comme Walker Evans, elle n'en fut pas moins de ceux qui développèrent le genre de " photographie de rue » qui devait devenir la marque de fabrique de la photographie américaine des années 40 à 80 dans le sillage de la photographie comme pilier de la modernité urbaine.

2 Ses images à la fois spontanées et exigeantes montrent une population, souvent de jeunes enfants attrapés au vol, occupant l'espace de la rue, ou bien des dessins et graffitis, traces mystérieuses d'une présence dont on ne saura rien. En cela les photographies de Levitt sont anti-documentaires. Amie de Walker Evans et de James Agee, admiratrice de Cartier-Bresson, elle puise dans leur technique pour construire une œuvre qui s'écarte pourtant sensiblement de la leur. Alors que Evans et CartierBresson sont des formalistes radicaux, Levitt est avant tout une photographe du surgissement vital, dans un mode qui n'est pas sans faire penser à celui de Robert Frank. Plus instinctive et moins obsédée par l'idée de laisser une œuvre qu'eux, plus répétitive aussi en apparence, elle ne cessera, sa vie durant, de s'émerveiller devant l'énergie créatrice de l'espace urbain. Totalement attachée et identifiée à une ville qu'elle ne quittera pratiquement jamais, en tout cas pour le travail, elle ne voyagera jamais guère au-delà dans les quartiers populaires de New York, si bien qu'on a pu la présenter comme une sorte de naturaliste de la photographie. Mais son New York n'est en rien celui d'une Berenice Abbott. On ne le voit guère dans ses cadrages en plans moyens et serrés où l'environnement n'est souvent qu'évoqué comme contexte à l'existence. Cette focalisation newyorkaise fera que, paradoxalement et malgré plusieurs grandes expositions dont la première se tint dès 1943 au MoMA, et en dépit de ses liens avec la scène photographique contemporaine, elle restera au second plan. 
3 Ses images ont aujourd'hui retrouvé la faveur des spécialistes et du public avec la disparition de ce monde qui faisait son œuvre. Le pouvoir élégiaque de l'image photographique excelle à ce genre de transformation. Aujourd'hui, les rues sont de moins en moins des lieux de vie pour être vues comme des espaces de chaos, de confrontation, de violence faite à l'intégrité de l'individu. La notion de communauté qu'elle offrait de manière graphique s'est dissoute dans un discours communautariste. On peut, depuis quelque temps, grâce à un ensemble de publications, redécouvrir le monde de Levitt qui est caractérisé par une profonde dose de mystère. Toute photographie est un mystère (Arbus parlait de "secret à propos d'un secret »), mais celles de Levitt, par leur caractère thématiquement ciblé (plus que répétitif) conduisent le spectateur d'un sentiment de familiarité amusée et complice à l'incertitude. Elles sont faussement plaisantes, plus profondes qu'il n'y paraît (il suffit de voir à quel point elles peuvent se suffire elles-mêmes) et réellement inquiétantes.

4 Ma préférée est probablement cette danse de deux enfants, saisie dans une rue de New York dans les années 1940, image plutôt gaie, où ne semble pas régner grand mystère. C'est que le mystère n'est pas nécessairement le caché, mais réside aussi dans l'indicible, la suspension du sens. Beauté du geste, tension du corps de la jeune fille, abandon souple de celui du jeune garçon, yeux clos, enfants tout entiers plongés dans leur for intérieur. Noir, blanc, ombre, soleil, deux faces de leur monde à venir. Pourtant, dans l'abstraction de l'ici et maintenant, nulle leçon, nulle lecture à produire, nul message à décoder. Rien que le geste, suspendu à jamais par un autre geste, minuscule, celui d'un doigt sur un « déclencheur » qui a saisi pour l'éternité et fait se rejoindre ces deux enfants, comme les deux corps parfaits de l'urne grecque : «forever young and she be fair ».

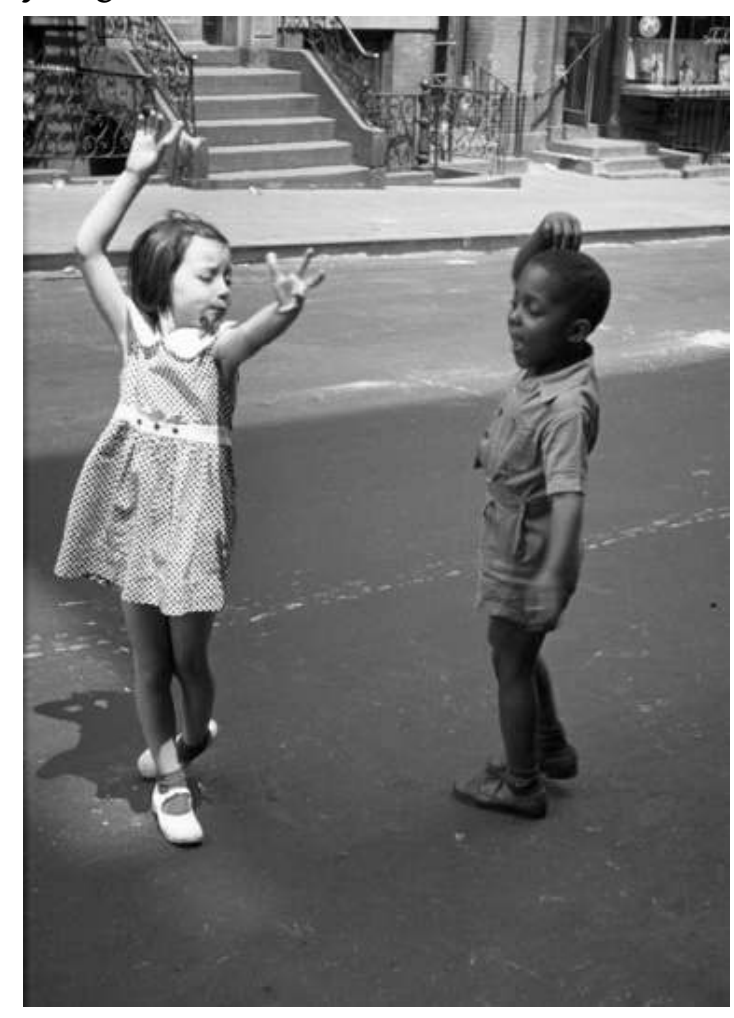

5 Voir article du New York Times (30 mars 2009): http://www.nytimes.com/2009/03/30/ arts/design/30levitt.html?_r=2 
INDEX

Thèmes : Trans'Arts

AUTEUR

JEAN KEMPF

Université Lyon 2 